\title{
Influence of Radiation on the Luminescence of Silicon Nanocrystals Embedded into $\mathrm{SiO}_{2}$ Film
}

\author{
I. P. Lisovskyy, ${ }^{1}$ M. V. Voitovych, ${ }^{1}$ V. V. Voitovych, ${ }^{2}$ and I. M. Khacevich ${ }^{1}$ \\ ${ }^{1}$ V.Ye. Lashkaryov Institute of Semiconductor Physics, National Academy of Sciences of Ukraine, Prosp. Nauki 41, Kyiv 03028, Ukraine \\ ${ }^{2}$ Institute of Physics, National Academy of Sciences of Ukraine, Prosp. Nauki 46, Kyiv 03028, Ukraine \\ Correspondence should be addressed to M. V. Voitovych; m201081@mail.ru
}

Received 14 July 2016; Revised 5 November 2016; Accepted 13 November 2016

Academic Editor: Giuseppe Compagnini

Copyright @ 2016 I. P. Lisovskyy et al. This is an open access article distributed under the Creative Commons Attribution License, which permits unrestricted use, distribution, and reproduction in any medium, provided the original work is properly cited.

Influence of $\gamma$-irradiation on light emission properties of silicon nanocrystals imbedded into $\mathrm{SiO}_{2}$ film is investigated. It was shown that small doses of $\gamma$-irradiation $\left(10^{3}-10^{5} \mathrm{rad}\right)$ lead to enhancement of photoluminescence intensity in the $\mathrm{nc}-\mathrm{Si} / \mathrm{SiO}_{2}$ samples. This effect was explained by radiation induced passivation of recombination active centers on the nanocrystals surface. High doses of irradiation $\left(\sim 10^{7} \mathrm{rad}\right)$ lead to the photoluminescence intensity decrease up to 2 times. Radiation treatment of silicon oxide films with embedded amorphous silicon inclusions resulted only in the decrease of the photoluminescence intensity within the whole range of doses $\left(10^{3}-5 \times 10^{7} \mathrm{rad}\right)$. Radiation defects resulting in partial quenching of photoluminescence are characterized with the distributed activation energy of annealing with the peak position at $\sim 0.96 \mathrm{eV}$ and the frequency factor $10^{7} \mathrm{~s}^{-1}$. The nature of such defects and the mechanisms of their creation are discussed.

\section{Introduction}

It is well known that intensive irradiation of silicon dioxide films in vacuum is capable to form silicon nanocrystals in the result of radiation induced reduction of $\mathrm{SiO}_{2}[1,2]$. This phenomenon and the corresponding mechanisms have been studied in detail. At the same time, study of influence of ionizing radiation on the properties of $\mathrm{SiO}_{2}$ films with imbedded $\mathrm{Si}$ nanocrystals (nc-Si/SiO${ }_{2}$ film structures) was attended much less. On the one hand, Si nanocrystals are predicted to have high radiation hardness [3]. In fact, significant degradation of photoluminescence (PL) of the porous silicon, connected with radiation defects creation, was observed after irradiation by rather high doses $\left(2 \times 10^{9}-10^{10} \mathrm{rad}\right)[4$, 5]. Effects of PL intensity enhancement after exposure by lower doses $\left(4.3 \times 10^{6}-3 \times 10^{8} \mathrm{rad}\right)[6]$ were observed only in the case of irradiation in air atmosphere [5] and were attributed to additional oxidation of porous $\mathrm{Si}$ surface under corrosive action of ozone, atomic oxygen, and hydrogen that were formed by illumination. This led to reduction of the concentration of nonradiative recombination centers on the surface of silicon nanocrystals and sometimes to decrease of their size.

On the other hand, one may expect that ionizing irradiation with quanta or particles (X-and $\gamma$-rays, electrons) is capable of substantially changing the emitting characteristics of the $\mathrm{nc}-\mathrm{Si} / \mathrm{SiO}_{2}$ film structures, taking into account a high radiation sensitivity of the $\mathrm{Si}-\mathrm{SiO}_{2}$ interface. The latter is known results in growth of the fast surface states density, these states being related with silicon to broken bonds [7-9]. In fact, certain enhancement ( 1.5 times) of luminescent intensity was observed by us earlier [10] after low dose $\left(\sim 10^{4} \mathrm{rad}\right)$ ionizing irradiation ( $\gamma$-ray photons) of $\mathrm{SiO}_{2}$ films with embedded Si nanocrystals. Contrary to the case of porous silicon, this effect in $\mathrm{nc}-\mathrm{Si} / \mathrm{SiO}_{2}$ structures was observed after radiation treatment even in the inert gas or in vacuum; hence, it had another nature. Recently, the authors of [11] reported that proton irradiation (the energy $3.5 \mathrm{MeV}$ and the total fluence $10^{12}-10^{15} \mathrm{~cm}^{-2}$ ) of nc-Si in $\mathrm{SiO}_{2}$ multilayers leads to significant decrease of the intensity of luminescence 
centered near $730 \mathrm{~nm}$, and in appearance of the luminescence band near $\sim 500 \mathrm{~nm}$, assigned to radiative recombination at the radiation induced centers within $\mathrm{a}-\mathrm{SiO}_{2}$ matrix. Larger exposure doses $\left(\sim 10^{6}-10^{7} \mathrm{rad}\right)$, similarly to the case of the porous silicon, led to a partial quenching of PL of the nc$\mathrm{Si} / \mathrm{SiO}_{2}$ films [10]. Investigation of just this effect to elucidate the nature of the radiation defects created under ionizing exposure of $\mathrm{nc}-\mathrm{Si} / \mathrm{SiO}_{2}$ films has been done in the present paper, study of the process of radiation damage annealing being mainly attended.

\section{Experimental}

$\mathrm{SiO}_{x}$ films $(x \approx 1.12)$ have been produced by thermal evaporation of $\mathrm{SiO}$ powder (Cerac Inc., purity of 99.9\%) in vacuum $\left(2 \times 10^{-3} \Pi \mathrm{\Pi}\right) . \mathrm{SiO}_{x}$ film thickness was measured after the deposition by the microinterferometer MII- 4 and amounted to $450 \mathrm{~nm}$. Several $\mathrm{SiO}_{x}$ films were implanted with nitrogen ions $\mathrm{N}^{+}$with the energies of 70 and $140 \mathrm{\kappa eV}$ and with the total dose of $8.4 \times 10^{15} \mathrm{~cm}^{-2}$ (further $\mathrm{nc}-\mathrm{Si} / \mathrm{SiO}_{2}: \mathrm{N}$ structures). SIMS measurements have confirmed a uniform distribution of the nitrogen in $\mathrm{SiO}_{x}$ film with depth.

$\mathrm{SiO}_{x}$ films were thermally treated in the argon ambient at $700^{\circ} \mathrm{C}$ or at $1100^{\circ} \mathrm{C}$ for $30 \mathrm{~min}$. As it was demonstrated by us earlier [12] using electron diffraction and the high resolution transmission electron microscopy, these thermal treatments resulted in creation of amorphous $\mathrm{Si}$ nanoinclusions (na-Si) imbedded into oxide matrix $\mathrm{SiO}_{y}(y \approx 1.24)$ or of crystalline Si nanoinclusions (nc-Si) about $3 \mathrm{~nm}$ in size homogeneously distributed within the $\mathrm{SiO}_{2}$ matrix, correspondingly.

Infrared (IR) transmission spectra were measured using FTIR spectrometer Spectrum BXII PerkinElmer. A silicon substrate (without oxide film) served as the reference sample. The absorption band related to $\mathrm{Si}-\mathrm{O}$ bonds (maximum position within the range of $1000-1100 \mathrm{~cm}^{-1}$ depending on the oxygen content in the oxide film) was under investigation.

Photoluminescence (PL) spectra were measured at room temperature within the spectral range of 550-1000 nm under the excitation at the $473 \mathrm{~nm}$ from the semiconductor laser. The excitation power was about $50 \mathrm{~mW}$. Measured PL spectra were corrected with respect to the spectral sensitivity of measurement setup.

Creation of $\mathrm{Si}$ nanocrystals in the nc-Si/SiO${ }_{2}$ and nc$\mathrm{Si} / \mathrm{SiO}_{2}: \mathrm{N}$ structures due to high temperature annealing resulted in appearance of rather strong red PL band (peak position in the vicinity of $800 \mathrm{~nm}$, see curve 1 in Figure 1(a)), corresponding value of the energy of light emission $(\sim$ $1.6 \mathrm{eV}$ ) being in agreement with that calculated or found experimentally for $\mathrm{nc}-\mathrm{Si}$ with the size of $\sim 3 \mathrm{~nm}$ [13]. PL intensity for the samples doped with nitrogen was by 3 times larger (see curve 1 in Figure 1(b)), which is also agreed with the data [14]. In the case of na- $\mathrm{Si} / \mathrm{SiO}_{y}$ samples, PL band was blue shifted (peak position at $\sim 680 \mathrm{~nm}$, see curve 1 in Figure 1(c)) that is in agreement with the known results [15]. The value of corresponding energy $(E)$ enabled us to estimate the size $(d)$ of amorphous Si inclusions, using phenomenological dependence $E=1.56+2.40 d^{-2}[16]$ : it was $\sim 3.2 \mathrm{~nm}$. na- $\mathrm{Si} / \mathrm{SiO}_{y}, \mathrm{nc}-\mathrm{Si} / \mathrm{SiO}_{2}$, and nc-Si/SiO${ }_{2}: \mathrm{N}$ samples were irradiated with $\gamma$-quanta $\left({ }^{60} \mathrm{Co}\right)$ with the intensity $36.77 \mathrm{rad} \cdot \mathrm{s}^{-1}$ and the energies 1.17 and $1.33 \mathrm{MeV}$. The dose of exposure varied in the range of $10^{3} \div 5 \times 10^{7} \mathrm{rad}$. The temperature of the samples during $\gamma$-irradiation did not exceed $30^{\circ} \mathrm{C}$. Irradiation was carried out both in air atmosphere and in vacuum $\left(10^{-3}\right.$ Torr $)$.

Set of irradiated samples was subjected to isochronous (50 $\left.\leq T \leq 300^{\circ} \mathrm{C}, \Delta T=10^{\circ} \mathrm{C}\right)$ and isothermal $(\Delta t=2 \mathrm{~min})$ anneals in argon atmosphere.

\section{Results and Discussion}

Figure 1 demonstrates influence of radiation on the PL red band for the nc-Si/SiO 2 (a), nc-Si/SiO $2: \mathrm{N}($ b), and na-Si/SiO (c) samples. Dose dependences of normalized PL intensity $\left(I_{\mathrm{PL}}^{R} / I_{\mathrm{PL}}^{i}\right.$, where $I_{\mathrm{PL}}^{R}$ and $I_{\mathrm{PL}}^{i}$ are the values of $\mathrm{PL}$ intensity for irradiated and initial samples, resp.) for all investigated structures are presented in Figure 2. It is seen that behavior of the samples under irradiation is different depending on the type of structure: the na- $\mathrm{Si} / \mathrm{SiO}_{y}$ samples are the less sensitive to influence of exposure. Moreover, for $\mathrm{Si} / \mathrm{SiO}_{2}: \mathrm{N}$ and na$\mathrm{Si} / \mathrm{SiO}_{y}$ structures $\mathrm{PL}$ intensity monotonically decays with the time of irradiation within the whole range of exposure doses. In contrast to this the dependence of $I_{\mathrm{PL}}$ on the exposure dose for the nc-Si/ $\mathrm{SiO}_{2}$ structures is nonmonotonous. In the range of irradiation doses less than $\sim 10^{5}$ rad the "low dose effect" was observed. This effect consisted in the remarkable $(\sim 1.7$ times) increase of PL intensity with respect to that for the initial sample. Further irradiation resulted in decrease in the PL intensity, which becomes smaller than the initial one at the irradiation doses above $5 \times 10^{5} \mathrm{rad}$. "Low dose effect" was observed in the $\mathrm{nc}-\mathrm{Si} / \mathrm{SiO}_{2}$ samples irradiated both in air atmosphere and in vacuum. This indicates (contrary to the case of porous silicon) the mechanism related to the interaction of $\gamma$-quanta with the sample, but not atmosphere influence.

The "low dose effect" was explained earlier [10] by passivation of silicon broken bonds on the surface of ncSi inclusions with hydrogen atoms and hydroxyls, which are released in oxide matrix due to decomposition of $\mathrm{SiH}$ and $\mathrm{SiOH}$ complexes under irradiation. Data obtained here for the case of irradiation of $\mathrm{nc}-\mathrm{Si} / \mathrm{SiO}_{2}: \mathrm{N}$ structures seem to confirm such a hypothesis. In these structures silicon broken bonds at nc-Si-SiO $\mathrm{S}_{2}$ interface have been partially or completely passivated by nitrogen atoms during the process of sample formation $[14,17,18]$, that is why initial PL intensity for $\mathrm{nc}-\mathrm{Si} / \mathrm{SiO}_{2}: \mathrm{N}$ samples was three times higher comparing to ordinary nc-Si/ $/ \mathrm{SiO}_{2}$ ones. Additional passivation under irradiation of a rather small amount of remaining defects is negligible and does not influence $I_{\mathrm{PL}}$; thus the irradiation of nc-Si $/ \mathrm{SiO}_{2}: \mathrm{N}$ systems led to monotonous $I_{\mathrm{PL}}$ decrease only (see Figures 1(b) and 2).

High doses of irradiation resulted in essential decay of the PL intensity (see Figures 1 and 2). It was expected and may be connected with creation of radiation defects at nc-Si/SiO interface, which are the centers of nonradiative recombination. Such processes were widely studied earlier in planar 


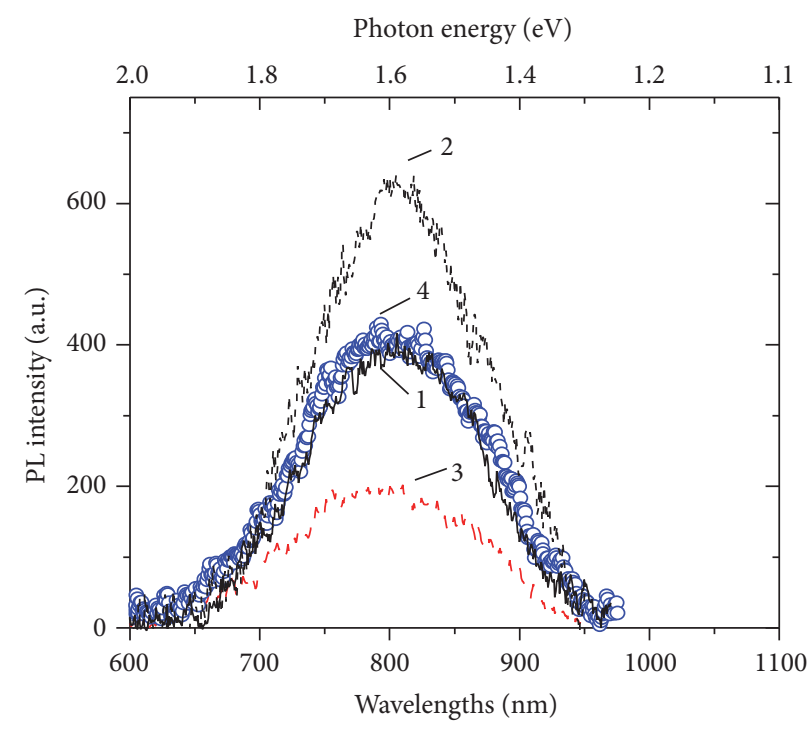

(a)

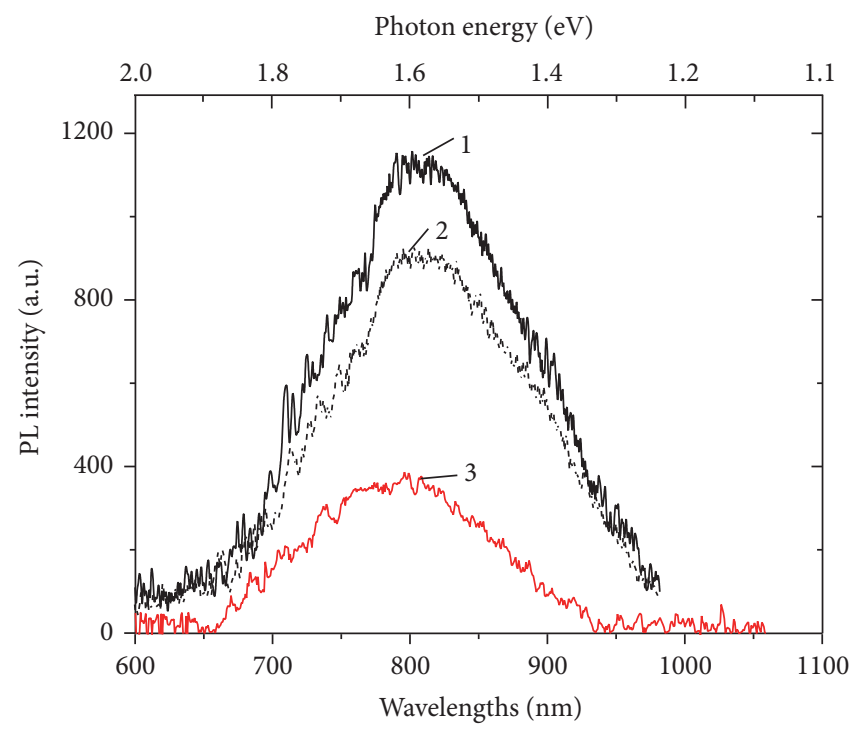

(b)

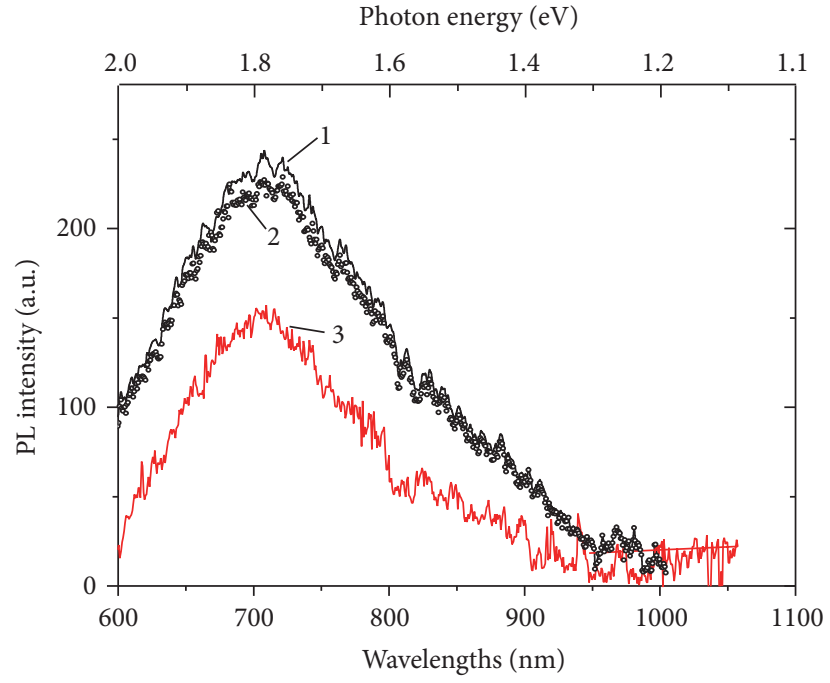

(c)

Figure 1: PL spectra for nc-Si/SiO 2 (a), nc-Si/SiO $2: \mathrm{N} \mathrm{(b),} \mathrm{and} \mathrm{na-Si/SiO}$ (c) samples. Curves notation: 1 , initial samples; 2 and 3 , samples irradiated with the doses of $2 \times 10^{4} \mathrm{rad}$ and $2 \times 10^{7} \mathrm{rad}$, respectively; 4 , sample irradiated $\left(2 \times 10^{7} \mathrm{rad}\right)$ and annealed at $T=300^{\circ} \mathrm{C}$.

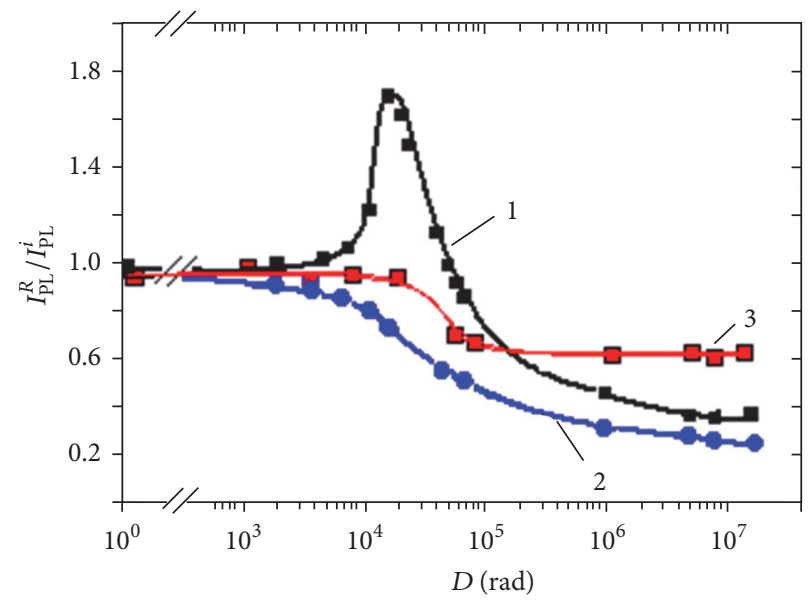

FIGURE 2: Dose dependence of PL band intensity for nc-Si/SiO $\mathrm{Si}_{2}(1), \mathrm{nc}-\mathrm{Si} / \mathrm{SiO}_{2}: \mathrm{N}(2)$, and na-Si/SiO${ }_{y}$ (3) structures. 
$\mathrm{Si} / \mathrm{SiO}_{2}$ systems and, naturally, the general corresponding approaches may be spread for the case of oxide films with embedded silicon nanoinclusions. However, observation of low dose effect in nc-Si/SiO ${ }_{2}$ structures enabled us to suppose that there are two competing processes, namely, those leading to enhancement of $I_{\mathrm{PL}}$ and those quenching it (formation of nonradiative recombination centers). Low doses of ionizing radiation lead to radiation stimulated passivation of $\mathrm{Si}$ dangling bonds at the nc-Si-SO $\mathrm{S}_{2}$ interface, which is more efficient comparing to formation of nonradiative recombination centers. Increase of $I_{\mathrm{PL}}$ is observed in result. Passivation can be provided by, for example, the hydrogen atoms and hydroxyls, which are formed in the oxide matrix due to decomposition of $\mathrm{SiH}$ and $\mathrm{SiOH}$ complexes under the irradiation. Si nanocrystals in $\mathrm{nc}-\mathrm{Si} / \mathrm{SiO}_{2}$ systems play a role of the gettering centers, leading to rise in the efficiency of collection on their surfaces of mentioned passivating agent already at the room temperature.

Defect formation leading to decrease of $I_{\mathrm{PL}}$ becomes dominating at higher irradiation doses $\left(D>2 \times 10^{4} \mathrm{rad}\right)$. The equilibrium in both defect formation processes is obtained at the irradiation dose of $2 \times 10^{4} \mathrm{rad}$. At this dose, the concentration of passivated $\mathrm{Si}$ broken bonds becomes approximately equal to the concentration of formed nonradiative recombination centers.

Defects formed by irradiation may be eliminated due to low-temperature treatment in vacuum or in inert ambient, resulting in restoration of the PL intensity (see curve 4 in Figure 1(a)). At the same time, IR absorption band connected with stretching vibrations of oxygen atoms in Si-O-Si units (maximum position near $\sim 1090 \mathrm{~cm}^{-1}$ ) with the shape inherent for $\mathrm{SiO}_{2}$ phase [19] practically did not vary after irradiation within the whole dose range and lowtemperature heat treatments in inert ambient both of the initial and irradiated $\mathrm{nc}-\mathrm{Si} / \mathrm{SiO}_{2}$. This fact should mean that irradiation and thermal treatments used in this study did not affect the concentration and structural arrangement of the bridging oxygen atoms in the oxide matrix.

For clarification of the nature of radiation defects, which lead to PL quenching, as well as the mechanism of their formation, detailed study of the thermal annealing processes of radiation induced defects in $\mathrm{nc}-\mathrm{Si} / \mathrm{SiO}_{2}$ structures was carried out.

In Figure 3 the results of isochronal annealing (temperature step $\Delta T=10^{\circ} \mathrm{C}$, duration of anneal at every temperature $\Delta t=10$ minutes) are presented. It is seen that heat treatment of initial sample did not affect PL intensity within the whole range of temperatures $\left(50-300^{\circ} \mathrm{C}\right)$. In the case of irradiated sample, restoration of $I_{\mathrm{PL}}$ up to the initial state takes place in the temperature range of $200 \div 300^{\circ} \mathrm{C}$ (Figure 3 ).

Isothermal annealing $\left(200<T<300^{\circ} \mathrm{C}\right)$ demonstrated that defect elimination at every temperature is only partial. The temperature determines not only the annealing rate but also the amount of nonannealed portion $N$ of the radiation damage. This result is important and means [20] that the radiation defect annealing in $\mathrm{nc}-\mathrm{Si} / \mathrm{SiO}_{2}$ structures is characterized by not single activation energy but that distributed in some energy interval.

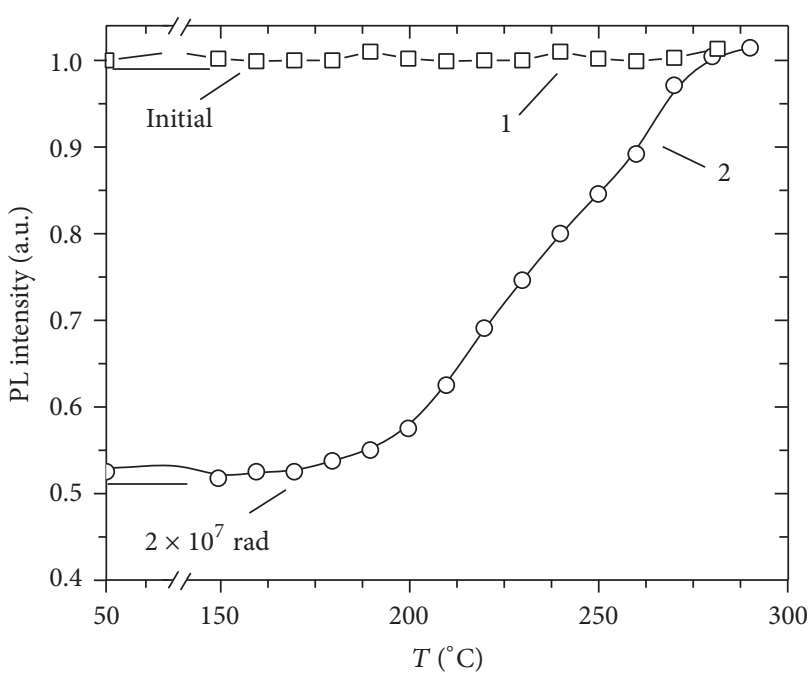

Figure 3: Dependence of the PL intensity on the annealing temperature for initial $\mathrm{nc}-\mathrm{Si} / \mathrm{SiO}_{2}$ sample (1) and $\mathrm{nc}-\mathrm{Si} / \mathrm{SiO}_{2}$ sample irradiated with the dose of $2 \times 10^{7} \mathrm{rad}(2)$.

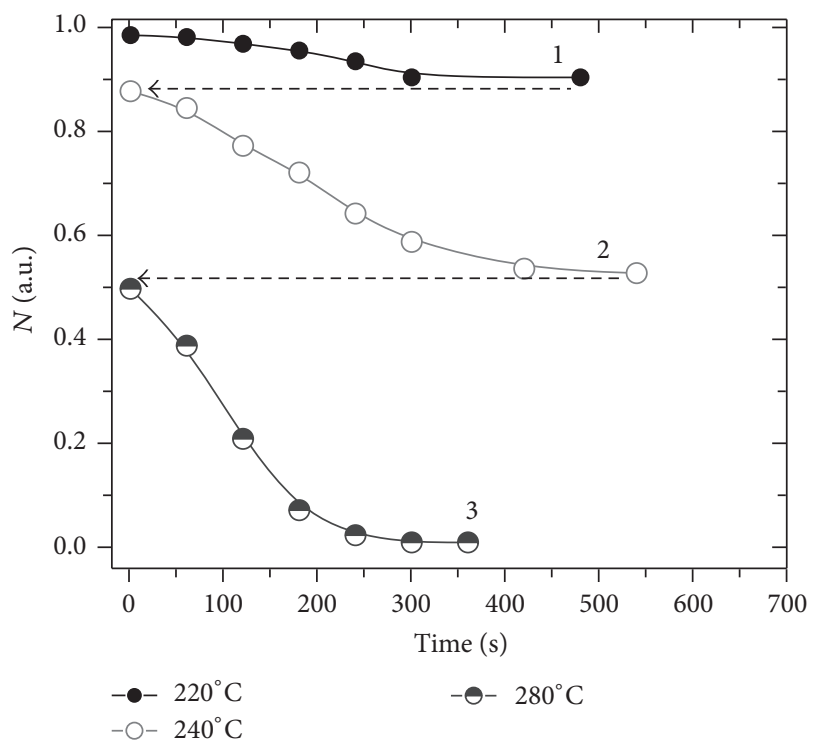

FIgURE 4: Curves of isothermal annealing for irradiated nc-Si/SiO sample.

To determine this activation energy distribution according to [20] a combined heat treatment of one sample was performed, consisting of three successive isothermal annealing cycles at 220,240 , and $280^{\circ} \mathrm{C}$. The results are presented in Figure 4 . Nonannealed portion of radiation damage was determined as

$$
N=\frac{I_{\mathrm{PL}}^{a}-I_{\mathrm{PL}}^{i}}{I_{\mathrm{PL}}^{R}-I_{\mathrm{PL}}^{i}}
$$

with $I_{\mathrm{PL}}^{i}, I_{\mathrm{PL}}^{R}$, and $I_{\mathrm{PL}}^{a}$ being the PL intensity for nonirradiated, irradiated, and annealed samples, respectively. 


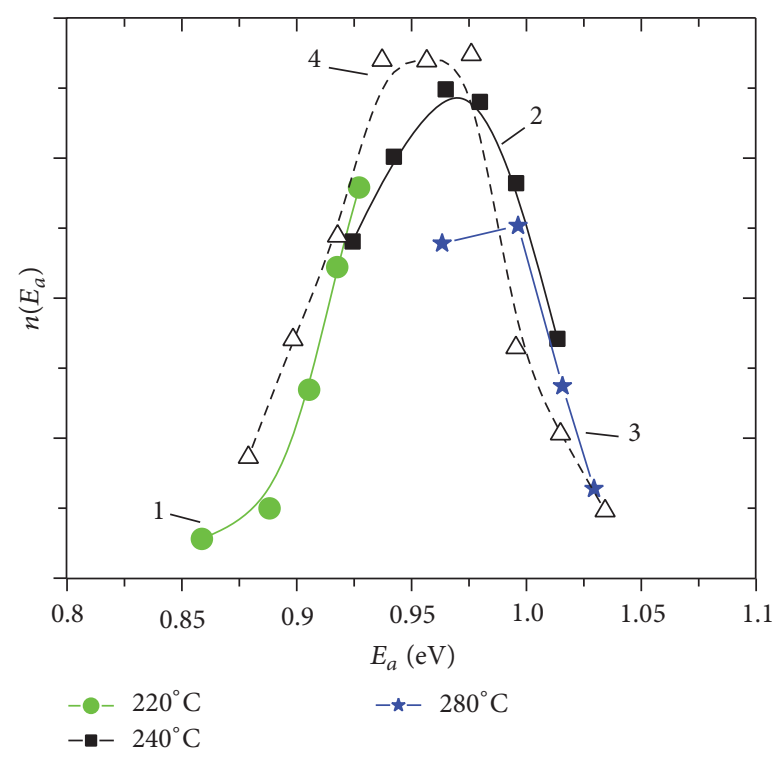

FIGURE 5: Distribution of the activation energy of annealing of radiation damage in $\mathrm{nc}-\mathrm{Si} / \mathrm{SiO}_{2}$ structure. Segments were obtained from the results of isothermal annealing. Curve 4 was obtained from the results of isochronous annealing. The value of $A$ is $10^{7} \mathrm{~s}^{-1}$. Triangles reflect the results obtained from analysis of isochronal annealing, which is described in the caption of Figure 5.

Using the data obtained for the annealing experiments the activation energy $E_{a}$ and the energy distribution function $n\left(E_{a}\right)$ were calculated from the following expressions [20, 21]:

$$
\begin{gathered}
E_{a}=\tau \ln (A t), \\
n\left(E_{a}\right)=-\left(\frac{t}{\tau}\right)\left(\frac{d N}{d t}\right)
\end{gathered}
$$

for the isothermal anneals and

$$
\begin{gathered}
\frac{E_{a}}{\tau}+\ln \left(\frac{E_{a}}{\tau}\right)=\ln A \Delta t, \\
n\left(E_{a}\right)=-\left(\frac{d N}{d \tau}\right)\left(\frac{E_{a}}{\tau}\right)^{-1}
\end{gathered}
$$

for isochronous annealing, respectively. In expressions (2) to (3), $\tau=k T$ is the thermal treatment time and $A$ is the frequency factor, respectively.

Using expressions (2) to (3) for each isothermal annealing cycle (Figure 4), the energy distribution functions were built (Figure 5). The value of $A\left(A=10^{3}-10^{10} \mathrm{~s}^{-1}\right)$ was fitted at the calculations of $n\left(E_{a}\right)$ so as to provide a continuity of distribution between different segments (each of which corresponded to certain isotherm in Figure 4). The best fit corresponded to $A=10^{7} \mathrm{~s}^{-1}$. It can be seen that the calculated distribution function curves based on different experiments (isothermal and isochronous annealing) have a good agreement. The activation energy of annealing of radiation defects that results in a partial decrease in $I_{\mathrm{PL}}$ in the nc- $\mathrm{Si} / \mathrm{SiO}_{2}$ structures is distributed in the range of $0.85-$ $1.05 \mathrm{eV}$ with the peak at $\sim 0.96 \mathrm{eV}$.
The values of $E_{a}$ and $A$ were compared to those for the radiation defects both in the single crystal Si bulk and in the planar $\mathrm{Si} / \mathrm{SiO}_{2}$ systems as well as in the near surface oxidized Si layer [20, 22-25]. It is well known that the primary radiation defects in silicon crystals have rather small values of the activation energy of annealing (in the case of vacancies, for example, the value of $E_{a}$ amounts the meanings of 0.18 and $0.33 \mathrm{eV}$ for $n$ - and $p$-Si, resp. [25]). The most part of the secondary radiation defects (in particular, agglomerations of the primary defects with impurity atoms) has $E_{a}$ values much larger (e.g., complexes of vacancies with oxygen atoms) or much less (e.g., complexes of vacancies with donor impurities). Only some secondary radiation defects in silicon crystals may have the values of $E_{a}$ similar to that calculated in this study. Thus, for example, Si-P6 defect, which includes $\mathrm{Si}$ interstitial atoms, is characterized with $E_{a}=0.92 \mathrm{eV}$; however it was observed only after neutron irradiation [25]. Vacancy-phosphorous atom complexes ( $E$ centers) have the value of $E_{a}=0.95 \mathrm{eV}$ [25], but the frequency factor of their annealing process is too high $\left(A=7 \times 10^{8} \mathrm{~s}^{-1}\right)$, and appearance of such defects in the $\mathrm{nc}-\mathrm{Si} / \mathrm{SiO}_{2}$ samples seems to be unexpected.

However, the data discussed above are related to the defects which are localized within the bulk of Si crystals. Presence of surface may influence temperature stability of radiation defects. It is known, in particular, that the surface layer (about $2 \mu \mathrm{m}$ in depth) of oxidized Si single crystals differs from silicon bulk both by larger sensitivity to ionizing radiation and by parameters of radiation damage annealing [26]. Silicon nanocrystals with the diameter of some nanometers embedded into $\mathrm{SiO}_{2}$ matrix and thus strongly mechanically stressed [27] are more similar to such a surface layer than to silicon bulk. Hence, it seems to be more correct to compare the calculated annealing parameters with those obtained for surface layer of irradiated oxidized silicon crystals. Investigations of the generation life time of the minor carriers in the silicon space charge region under $\gamma$ irradiation (with the dose up to $10^{6} \mathrm{rad}$ ) made it possible to determine the value of the activation energy of annealing of the corresponding surface radiation defects; it amounted (in the maximum of distribution) the meanings of $1.1-1.2 \mathrm{eV}$ depending on the oxidizing technology regimes [26]. This value also differs from that calculated in the present study.

However, it can be easily shown that in our experiments radiation defects, which have been created in silicon nanocrystals, can not influence their light emitting ability. In fact, it is well known that in Si one $\gamma$-quant may form about $10^{-3} \mathrm{~cm}^{-3}$ of primary radiation defects [28]. Then the number of the point defects, which have been generated in the bulk of all silicon nanocrystals (with the diameter of $\sim 3 \times 10^{-9} \mathrm{~m}$ and the concentration of $\sim 10^{18} \mathrm{~cm}^{-3}$ ) after irradiation with the dose of $2 \times 10^{7} \mathrm{rad}$ ( or $\sim 3.4 \times 10^{16} \gamma$-quanta), should be about $10^{13} \mathrm{~cm}^{-3}$. On the other hand, a decrease in the PL intensity in the nc-Si/SiO 2 structures is known [29] and may be observed if the concentration of the centers of nonradiative recombination amounts the value of $10^{16}-10^{18} \mathrm{~cm}^{-3}$. Thus, one can conclude that in the irradiated $\mathrm{nc}-\mathrm{Si} / \mathrm{SiO}_{2}$ structures 
radiation defects, which influence the PL intensity value, are not localized within the bulk of silicon nanocrystals.

Some decades ago the processes of radiation damage creation and elimination in the MOS structures have been studied intensively. In particular, the values of activation energy of annealing both the centers in the oxide and the fast surface states at the $\mathrm{Si}-\mathrm{SiO}_{2}$ interface which were created in the result of different kinds of radiation treatment have been determined [20, 24, 26]. In all the cases activation energy was distributed along the energy axe with the peak position near $0.9 \mathrm{eV}$, and the meaning of the frequency factor was $10^{7} \mathrm{~s}^{-1}$. These values practically coincide with those calculated in the present work. Hence, one may conclude that the radiation defects, which are formed by $\gamma$-irradiation of $\mathrm{nc}-\mathrm{Si} / \mathrm{SiO} \mathrm{O}_{2}$ structures and lead to partial quenching of luminescence, are located, namely, at the $\mathrm{nc}-\mathrm{Si}-\mathrm{SiO}_{2}$ interfaces. These defects are the centers of nonradial recombination, their nature and the formation mechanism being identical to those characterizing the radiation surface states in $\mathrm{Si} / \mathrm{SiO}_{2}$ planar systems.

The most probable radiation induced defects at the $\mathrm{Si}-$ $\mathrm{SiO}_{2}$ interface are the silicon broken bonds $\mathrm{Si}^{3+}$ [9]. However, some alternative models exist to explain the mechanism of these defects creation due to active treatments (irradiation, hot carriers injection) $[9,30,31]$. Their main mutual feature is that surface states are the secondary defects; the process of radiation damage generation under irradiation takes place in $\mathrm{SiO}_{2}$ film. In fact, the concentration of the silicon broken bonds, which are created by ionizing radiation within the oxide films at the doses of $10^{6}-10^{7} \mathrm{rad}$, amounts the value of $10^{18}-10^{19} \mathrm{~cm}^{-3}$ [32]. This number is not sufficient to influence the $\mathrm{Si}-\mathrm{O}$ absorption band, but sufficiently large to affect the $\mathrm{PL}$ intensity in the case of $\mathrm{nc}-\mathrm{Si} / \mathrm{SiO}_{2}$ samples.

\section{Conclusions}

Gamma irradiation of $\mathrm{nc}-\mathrm{Si} / \mathrm{SiO}_{2}$ structures with low $\left(<10^{5} \mathrm{rad}\right)$ doses both in air and in vacuum resulted in pronounced rise in PL intensity. This effect was explained by radiation assisted passivation of centers of nonradiative recombination at $\mathrm{nc}-\mathrm{Si}-\mathrm{SiO}_{2}$ interfaces. "Low dose" effect was absent in the case of na-Si/SiO ${ }_{y}$ and nc-Si/SiO $2: \mathrm{N}$ structures, where irradiation only led to monotonous decrease in the PL intensity.

Larger doses of $\gamma$-irradiation of $\mathrm{nc}-\mathrm{Si} / \mathrm{SiO}_{2}$ structures resulted in the formation of radiation induced defects that significantly (twice at $10^{7} \mathrm{rad}$ ) quench the photoluminescence. These defects are annealed due to heat treatments at the temperatures in the range of $200 \div 300^{\circ} \mathrm{C}$. The activation energy of annealing is distributed within the energy range of $0.85-1.05 \mathrm{eV}$ with the peak at $\sim 0.96 \mathrm{eV}$. The frequency factor is $10^{7} \mathrm{~s}^{-1}$. The values of $E_{a}$ and $A$ coincide practically with those determined for the fast surface states formed at the $\mathrm{Si}-\mathrm{SiO}_{2}$ interface by ionizing radiation. This fact allows one to infer the accumulation of radiation induced defects partially quenching the photoluminescence, at the Si nanocrystal/oxide matrix interface. The nature of these defects and the mechanism of their formation are the most likely similar to those pertinent to the surface states formed by ionizing radiation at the planar $\mathrm{Si}-\mathrm{SiO}_{2}$ interfaces.

\section{Competing Interests}

The authors declare that they have no competing interests.

\section{References}

[1] M. Takeguchi, K. Furuya, and K. Yoshihara, "Structure study of Si nanocrystals formed by electron-induced reduction of $\mathrm{SiO}_{2}$ at high temperature," Japanese Journal of Applied Physics, vol. 38, no. 12B, p. 7140, 1999.

[2] X.-W. Du, M. Takeguchi, M. Tanaka, and K. Furuya, "Formation of crystalline $\mathrm{Si}$ nanodots in $\mathrm{SiO}_{2}$ films by electron irradiation," Applied Physics Letters, vol. 82, no. 7, pp. 1108-1110, 2003.

[3] N. Gerasimenko and Yu. Parkhomenko, Silicon-Nanoelectronics Material, Teknosferra, Moscow, Russia, (Russian) 2007.

[4] E. V. Astrova, V. V. Emtsev, A. A. Lebedev et al., "Degradation of the photoluminesce of the porous silicon under the influence of gamma-radiation ${ }^{60}$ Co," Fizika i Tekhnika Poluprovodnikov, vol. 29, pp. 1301-1305, 1995 (Russian).

[5] E. V. Astrova, P. Wittmann, V. V. Emtsev et al., "Influence $\gamma$ radiation on properties of porous silicon," Fizika i Tekhnika Poluprovodnikov, vol. 30, pp. 507-514, 1996 (Russian).

[6] J. S. Fu, J. C. Mao, E. Wu et al., "Gamma-rays irradiation: an effective method for improving light emission stability of porous silicon," Applied Physics Letters, vol. 63, no. 13, pp. 1830$1832,1993$.

[7] C. T. Sah, "Origin of interface states and oxide charges generated by ionizing radiation," IEEE Transactions on Nuclear Science, vol. 23, no. 6, pp. 1563-1156, 1976.

[8] P. M. Lenahan and P. V. Dressendorfer, "Paramagnetic trivalent silicon centers in gamma irradiated metal-oxide-silicon structures," Applied Physics Letters, vol. 44, no. 1, pp. 96-98, 1984.

[9] F. J. Grunthaner and P. J. Grunthaner, "Chemical and electronic structure of the $\mathrm{SiO}_{2} /$ Si interface," Materials Science Reports, vol. 1, no. 2, pp. 65-160, 1986.

[10] I. P. Lisovskyy, I. Z. Indutnil̆, M. V. Muravskaya, V. V. Voitovich, E. G. Gule, and P. E. Shepelyavy̌́, "Enhancement of photoluminescence of structures with nanocrystalline silicon stimulated by low-dose irradiation with $\gamma$-ray photons," Semiconductors, vol. 42, no. 5, pp. 576-579, 2008.

[11] S. Jang, B. S. Joo, S. Kim et al., "Effects of proton irradiation on Si-nanocrystal/ $/ \mathrm{SiO}_{2}$ multilayers: study of photoluminescence and first-principles calculations," Journal of Materials Chemistry C, vol. 3, no. 33, pp. 8574-8581, 2015.

[12] A. Szekeres, T. Nikolova, A. Paneva et al., "Silicon nanoparticles in thermally annealed thin silicon monoxide films," Materials Science and Engineering: B, vol. 124-125, pp. 504-507, 2005.

[13] Y. Kanzawa, T. Kageyama, S. Takeoka, M. Fujii, S. Hayashi, and K. Yamamoto, "Size-dependent near-infrared photoluminescence spectra of $\mathrm{Si}$ nanocrystals embedded in $\mathrm{SiO}_{2}$ matrices," Solid State Communications, vol. 102, no. 7, pp. 533-537, 1997.

[14] M.-S. Yang, K.-S. Cho, J.-H. Jhe et al., "Effect of nitride passivation on the visible photoluminescence from Si-nanocrystals," Applied Physics Letters, vol. 85, no. 16, pp. 3408-3410, 2004.

[15] H. Rinnert, M. Vergnat, and A. Burneau, "Evidence of lightemitting amorphous silicon clusters confined in a silicon oxide matrix," Journal of Applied Physics, vol. 89, no. 1, pp. 237-243, 2001.

[16] H.-S. Kwack, Y. Sun, Y.-H. Cho, N.-M. Park, and S.-J. Park, "Anomalous temperature dependence of optical emission in visible-light-emitting amorphous silicon quantum dots," Applied Physics Letters, vol. 83, no. 14, pp. 2901-2903, 2003. 
[17] A. R. Wilkinson and R. G. Elliman, "The effect of annealing environment on the luminescence of silicon nanocrystals in silica," Journal of Applied Physics, vol. 96, no. 7, pp. 4018-4020, 2004.

[18] M. López, B. Garrido, C. García et al., "Elucidation of the surface passivation role on the photoluminescence emission yield of silicon nanocrystals embedded in $\mathrm{SiO}_{2}$," Applied Physics Letters, vol. 80, no. 9, pp. 1637-1639, 2002.

[19] I. P. Lisovskii, V. G. Litovchenko, V. G. Lozinskii, and G. I. Steblovskii, "IR spectroscopic investigation of $\mathrm{SiO}_{2}$ film structure," Thin Solid Films, vol. 213, no. 2, pp. 164-169, 1992.

[20] V. Danchenko, "Characteristics of thermal annealing of radiation damage in MOSFET's," Journal of Applied Physics, vol. 39, no. 5, pp. 2417-2424, 1968.

[21] W. Primak, "Kinetics of processes distributed in activation energy," Physical Review, vol. 100, no. 6, pp. 1677-1689, 1955.

[22] V. S. Vavilov, Radiation Effects in Semiconductors and Semiconductor Devices, Atomizdat, Moscow, Russia, 1969.

[23] V. G. Litovchenko, "Nature of radiation effects in layered MIS structures," Optoelectronics and Semiconductor Technology, vol. 25, pp. 27-35, 1982.

[24] I. P. Lisovskii, V. G. Litovchenko, and R. O. Litvinov, "Effect of UV illumination on the electrical properties of mos layer structures," Physica Status Solidi (A), vol. 53, no. 1, pp. 253-262, 1979.

[25] V. S. Vavilov, V. F. Kiselyov, and B. N. Mukashev, Defects in Silicon and on Its Surface, Nauka, Moscow, Russia, (Russian) 1990.

[26] V. Y. Kiblik, Investigation of the electro-physical characteristics of the MOS structures exposed to radiation treatments [Ph.D. thesis], 1982.

[27] B.-H. Kim, M. A. Pamungkas, M. Park, G. Kim, K.-R. Lee, and Y.-C. Chung, "Stress evolution during the oxidation of silicon nanowires in the sub-10 nm diameter regime," Applied Physics Letters, vol. 99, no. 14, Article ID 143115, 3 pages, 2011.

[28] V. M. Kulakov, V. I. Shakhovtsov, and S. I. Shakhovtsova, Comparative Efficiency of the Action of the Nuclear Radiation on the Semiconductor Materials, Naukova Dumka, Kyiv, Ukraine, 1978 (Russian).

[29] K. Sato and K. Hirakuri, "Influence of paramagnetic defects on multicolored luminescence from nanocrystalline silicon," Journal of Applied Physics, vol. 100, no. 11, pp. 114303-114306, 2006.

[30] V. G. Litovchenko, I. P. Lisovskii, and R. O. Litvinov, "Application of UV light for studying surface reactions in layer structures," Applications of Surface Science, vol. 6, no. 1, pp. 1528, 1980.

[31] D. M. Fleetwood, S. T. Pantelides, and R. D. Schrimps, Defects in Microelectronic Materials and Devices, Taylor \& Francis Group, LLC, Boca Raton, Fla, USA, 2008.

[32] A. N. Vologdin and A. P. Lysenko, Radiation Effects in Integral Circuits and the Test Methods of Radiation Resistance of Semiconductor Electronics Products, MGIAM, Moscow, Russia, 2002 (Russian). 

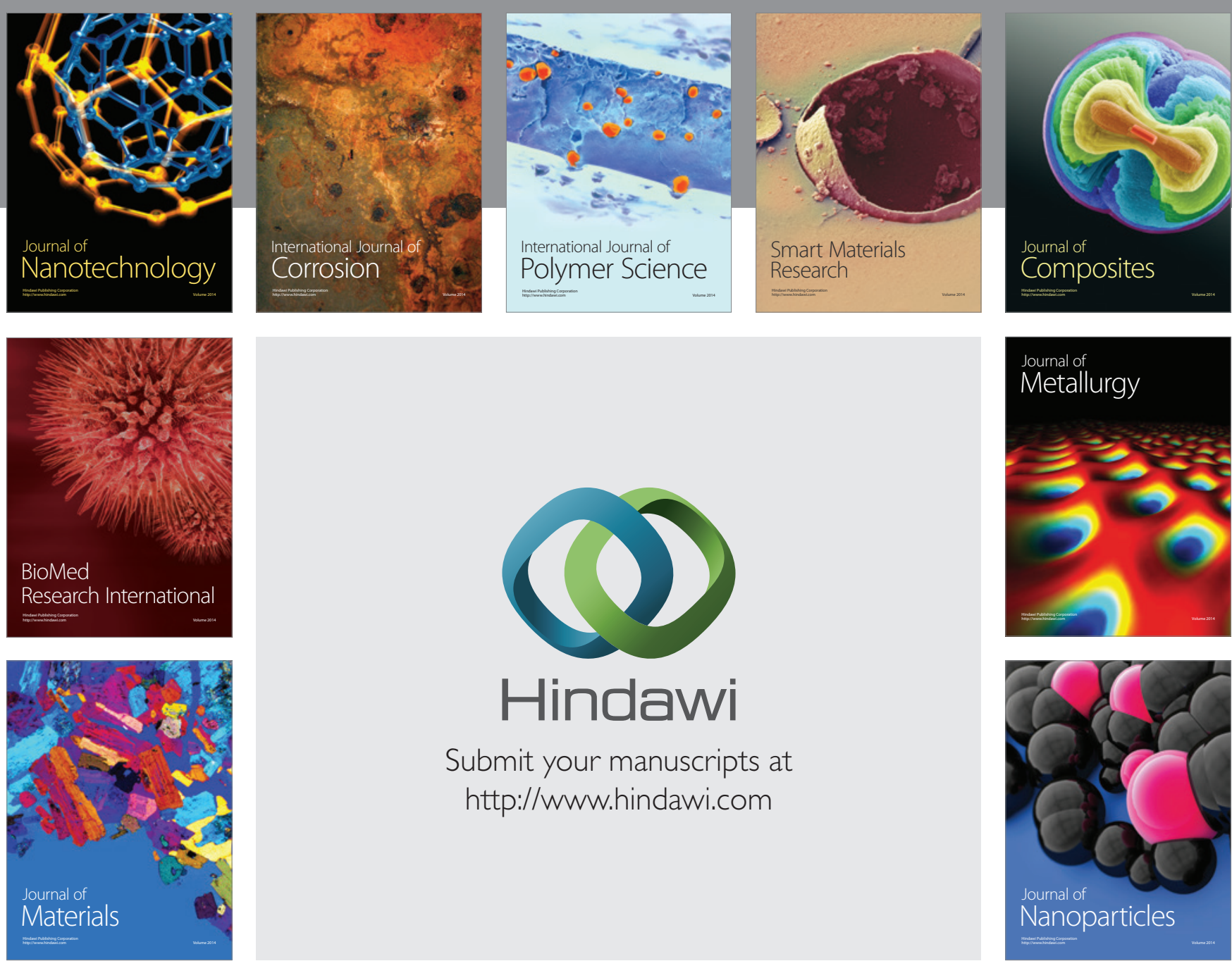

\section{Hindawi}

Submit your manuscripts at

http://www.hindawi.com

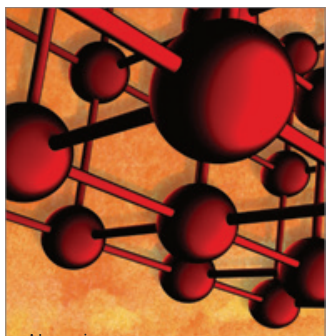

Materials Science and Engineering
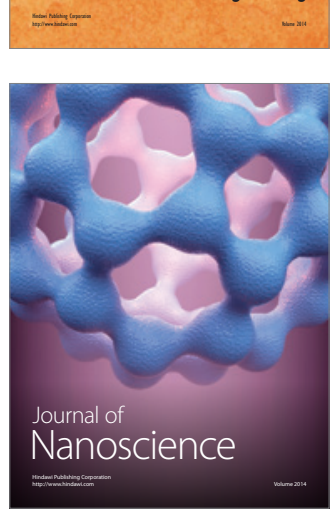
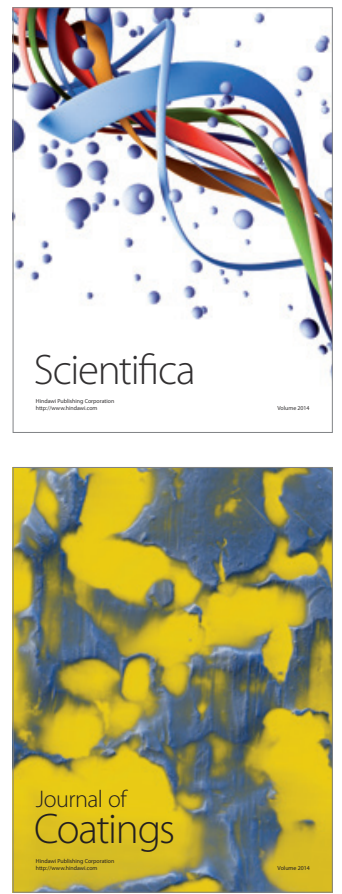
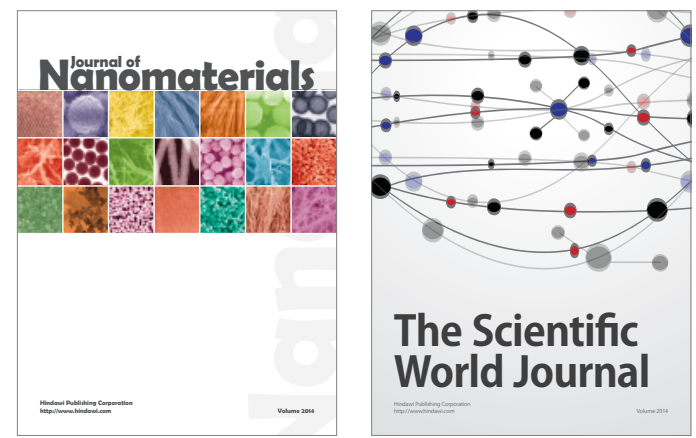

The Scientific World Journal
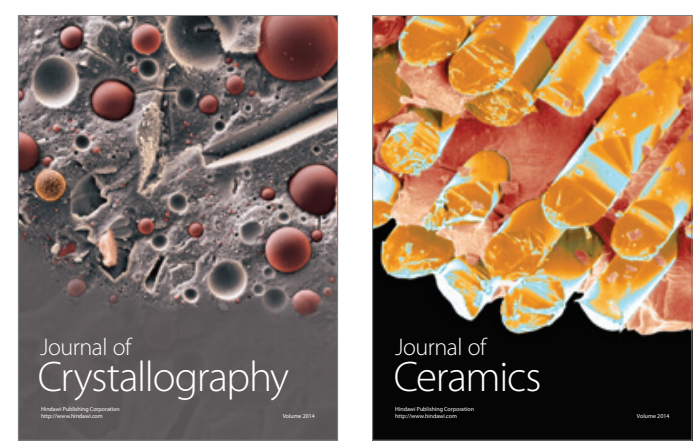
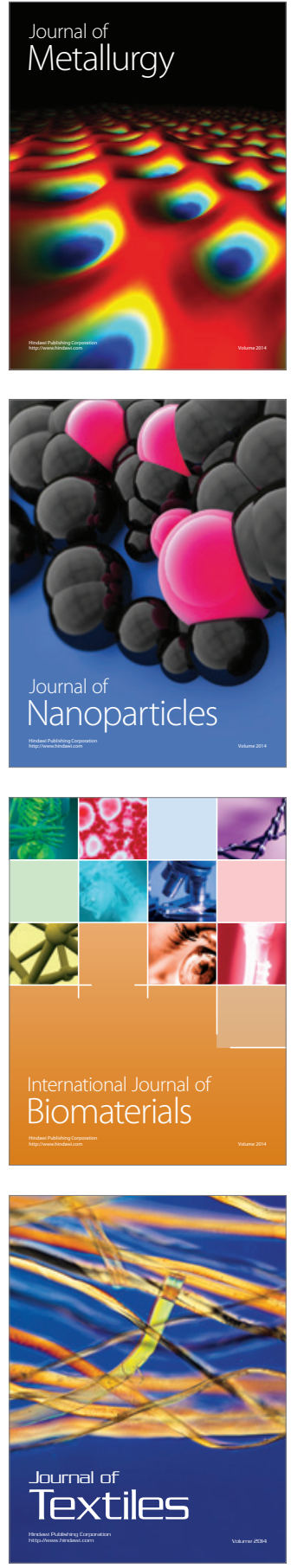